\title{
Fault Behaviour of a Superconducting Turboelectric Distributed Propulsion Aircraft Network:
}

\author{
A Comprehensive Sensitivity Study
}

\author{
K. M. Davies, P. J. Norman, C. E. Jones, S. J. Galloway, G. M. Burt \\ Institute for Energy and Environment \\ University of Strathclyde \\ Glasgow, UK \\ karen.davies@strath.ac.uk
}

\begin{abstract}
Variations in the network architecture and component choices of superconducting DC networks proposed for future aircraft propulsion systems could have a significant impact on their fault response. Understanding these potential variations is key to developing effective protection solutions for these aircraft applications. To this end, this paper presents the results of sensitivity studies conducted using a representative model of a faulted superconducting DC network in which key system parameters are varied. Of the parameters considered, network voltage and the cable dimensions are shown to have the greatest impact on fault current profile whilst the rate of change of fault current is shown to be sensitive to network voltage and cable length. The paper concludes by exploring the implications of these findings on the prospective protection strategy for future aircraft propulsion systems.
\end{abstract}

Keywords-superconducting DC networks; fault response; Turboelectric Distributed Propulsion

\section{INTRODUCTION}

Turboelectric Distributed Propulsion (TeDP) is currently being considered as a promising technology which will enable the improvement of fuel efficiency and the reduction of NOx and noise emissions of future passenger aircraft. In such an aircraft gas turbines power superconducting generators where the electrical power produced is supplied to an array of superconducting motors which provide the aircraft's thrust [1]. As TeDP is fully dependent on the reliability of the electrical power system to maintain a suitable standard of aircraft safety, the protection of this system is critically important.

Another major difference between a TeDP network and electrical systems present in the current fleet of aircraft is the deployment of superconducting technologies at almost every stage of the network (any power electronic converters employed are expected to operate at cryogenic temperatures [2]) from generator to propulsive motor. Currently there is a shortage of published work which details the network level fault behaviour of a fully superconducting DC network. In order to address this issue this paper presents a simplified model of a section of a superconducting TeDP network which is used to conduct a range of sensitivity studies. From these studies a number of key behavioural trends are identified that can be used to inform further work on architectural design and system protection.

\section{SUPERCONDUCTING DC NETWORKS FOR TEDP}

TeDP represents a dramatic change in the way that an aircraft's propulsion is provided. Gas turbines are used to power superconducting generators capable of producing large amounts of electrical power which is distributed to array of superconducting motors and propulsive fans via, in this case, a fully superconducting DC distribution network as shown in Fig. 1. TeDP effectively decouples the mechanical connection between the gas turbine and the fan, replacing it with an electrical connection which allows both components to be run at their most efficient speeds [3]. As the aircraft's thrust is now reliant upon the electrical system, effective architectural design and system protection are required to ensure the safety of the aircraft. For example, in the event of an engine failure the power generated from the healthy engine via its associated generators must be capable of maintaining a minimum level of thrust for safe operation. Additionally the ability to reroute this power to the affected fans will ensure minimal disruption to the operation of the aircraft.

One of the major benefits of a TeDP system is that under intended operating conditions an ideal superconducting DC network will have zero resistance, therefore eliminating power

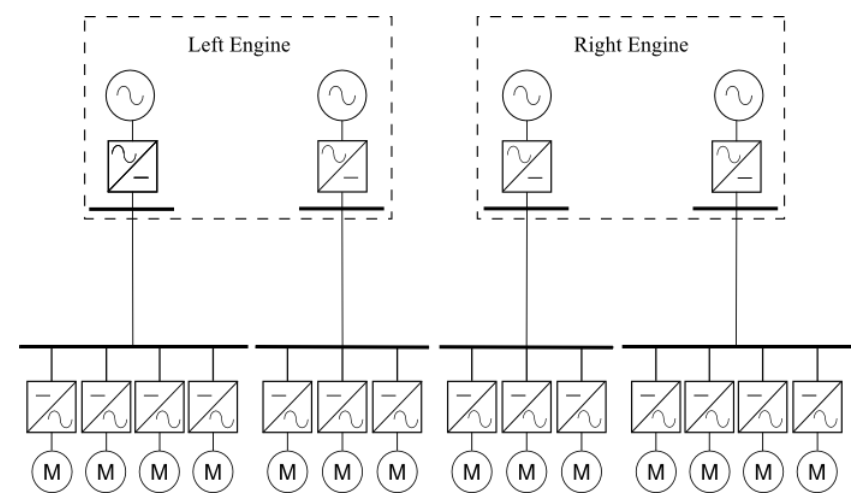

Fig. 1. A candidate architecture for a TeDP network. 


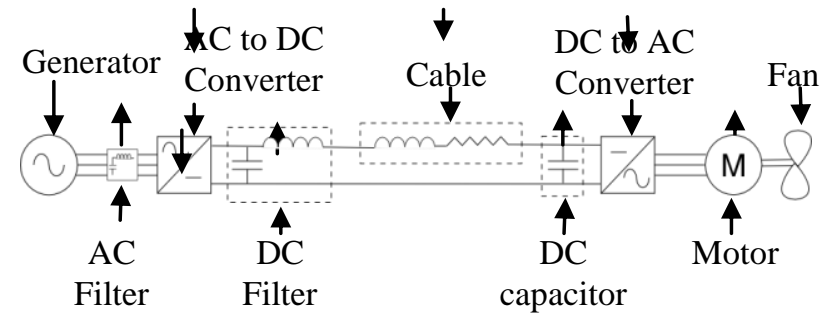

Fig. 2. Single branch of a TeDP network.

losses [4]. However the superconducting network also introduces many challenges regarding system protection. For example, under short circuit fault conditions the network will experience an initial rise in current. Due to the negligible resistance present in the network this fault current is likely to be higher than that of a conventional network. However, if the current in the superconducting cable exceeds its critical current, the cable will quench leading to a rise in resistance which naturally limits the current. Determining whether the network components will quench under fault conditions and, if so, the extent to which the network is damped due to this transient resistance, is essential to determining the protection requirements of the TeDP network.

It is also important to understand the behaviour of the network under different fault conditions, for which a qualitative Failure Modes and Effects Analysis (FMEA) was conducted and presented by the authors in [5]. This present paper builds upon the previously published study by investigating the fault behaviour of the network in a quantitative manner.

\section{Modelling The TeDP NeTwORK}

This study considers a single section of the network shown in Fig. 1 connecting a generator through to a single propulsion motor (as illustrated in Fig. 2). This circuit can be then further reduced to a representative RLC circuit (as illustrated in Fig. 3) [6] modelled using Matlab SimPowerSystems [7]. It is assumed that in the timescales of the fault transients considered, the contribution to the fault from the converter is negligible compared to the discharge from the passive filter components [6]. In Fig. 3, the term $C_{F}$ is the capacitance of the DC filter $(\mathrm{F}), L_{\text {cable }}$ is the inductance of the cable $(\mathrm{H}), R_{\text {cable }}$ is its resistance $(\Omega)$ and $R_{\text {fault }}$ is a low impedance fault placed across the cable $(\Omega) . V_{C F}(t)$ is the instantaneous voltage across the filter capacitance $(\mathrm{V})$ and $i_{L}(t)$ is the current in the network (A).

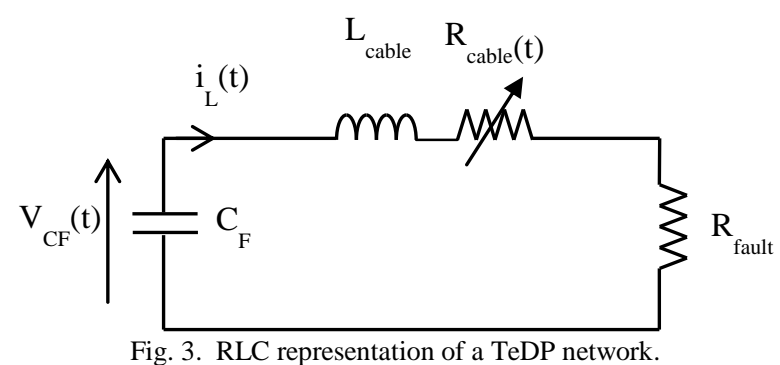

Under the intended operating conditions the resistance of the superconducting cable, $R_{\text {cable }}(t)(\Omega)$, is $0 \Omega$. Its instantaneous resistance is represented by a variable resistance triggered when the current in the cable exceeds the critical current, $I_{c}(\mathrm{~A})$, defined as

$$
I_{c}=J_{c} \times a_{\text {cable }} .
$$

The term $J_{c}$ is the critical current density of the cable $\left(\mathrm{A} / \mathrm{m}^{2}\right)$ and $a_{\text {cable }}$ is its cross sectional area $\left(\mathrm{m}^{2}\right)$.

If the current in the cable exceeds the critical current of the superconducting material its resistivity will increase at a rate of $k_{\text {quench }}(\Omega / \mathrm{s})$ until it reaches its quenched resistance, $R_{\text {quenched }}$ $(\Omega)$, as defined by

$$
R_{\text {quenched }}=\left(\rho_{\text {ambient }} \times a_{\text {cable }}\right) / l_{\text {cable }},
$$

where $\rho_{\text {ambient }}$ is the resistivity of the superconducting material at the ambient temperature of the system ( $77 \mathrm{~K}$ in this case) $(\mu \Omega \mathrm{m})$ and $l_{\text {cable }}$ is the length of the cable $(\mathrm{m})$.

In a real superconducting system the gradient of $k_{\text {creep }}$ is determined by the rise in temperature that occurs due to the increase in electrical heat dissipation during the quenching process. As resistivity is dependent on temperature, the resistance thus continues to increase further following a quench. However due to the limitations of this model, temperature is not taken into account and $k_{\text {creep }}$ is an approximation based on existing studies. Once the resistance reaches $R_{\text {quenched }}$ it will continue to increase at a reduced rate of $k_{\text {creep }}(\Omega / \mathrm{s})[8]$.

\section{SENSTIVITY StUdIES}

As there is still uncertainty in the specific values of key network parameters for a TeDP system, a range of sensitivity studies investigating the fault behaviour of the network in response to various changes in these parameters were conducted and are presented in this section of the paper. The aim of these sensitivity studies is to provide a valuable insight to the key behavioural trends which can be used to inform network and system protection design.

The parameters used in the following studies are

\begin{tabular}{|c|c|c|c|c|c|c|c|}
\hline & \multicolumn{6}{|c|}{ Network parameters } \\
\hline & & $\begin{array}{l}\rho_{\text {ambient }} \\
\boldsymbol{\mu} \boldsymbol{\Omega}\end{array}$ & $\begin{array}{l}\boldsymbol{k}_{\text {creep, }} \\
\boldsymbol{\Omega} / \mathbf{s}\end{array}$ & $\begin{array}{l}k_{\text {quench }}, \\
\boldsymbol{k} \boldsymbol{\Omega} / \boldsymbol{s}\end{array}$ & $\begin{array}{l}V_{C F}(0), \\
V\end{array}$ & $\begin{array}{l}l_{\text {cable, }} \\
\boldsymbol{m}\end{array}$ & $\begin{array}{l}d_{\text {cable, }} \\
m \boldsymbol{m}\end{array}$ \\
\hline \multirow{6}{*}{ 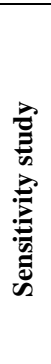 } & $\rho_{\text {ambient }}$ & $\begin{array}{l}0.01- \\
10\end{array}$ & 10 & 10 & 270 & 10 & 12 \\
\hline & $\boldsymbol{k}_{\text {creep }}$ & 1 & $\begin{array}{l}100- \\
1000\end{array}$ & 10 & 270 & 10 & 12 \\
\hline & $\boldsymbol{k}_{\text {quench }}$ & 1 & 10 & $1-100$ & 270 & 10 & 12 \\
\hline & $V_{C F}(0)$ & 1 & 10 & 10 & $\begin{array}{l}270- \\
10000\end{array}$ & 10 & 12 \\
\hline & $l_{\text {cable }}$ & 1 & 10 & 10 & 270 & $1-50$ & 12 \\
\hline & $d_{\text {cable }}$ & 1 & 10 & 10 & 270 & 10 & $10-30$ \\
\hline
\end{tabular}

Table 1. Network parameters used for sensitivity studies 
summarized in Table 1. Additional network parameters used in these simulations are: Pre-fault load current, $i_{L}(0)=20 \mathrm{~A}$; Fault resistance, $R_{\text {fault }}=10 \mathrm{~m} \Omega$.

\section{A. Resistivity, $\rho_{\text {ambient }}$}

The first variable considered is the resistivity of the cable material. The authors of [8] state that as the resistivity at the ambient temperature increases so does the gradient of $k_{\text {creep }}$ with respect to temperature.

Fig. 4 shows the fault current profile of the network for each set of resistivity and $k_{\text {creep }}$ values. It can be seen that the peak fault current is reduced dramatically from nearly $7 \mathrm{kA}$ to around $2 \mathrm{kA}$ when the resistivity at $77 \mathrm{~K}$ is $10 \mu \Omega \mathrm{m}$ compared with $0.01 \mu \Omega \mathrm{m}$. Increasing the resistivity has a lesser effect on the rate of change of fault current however. This is illustrated in Fig. 5, where it can be seen that the initial $d i / d t$ is approximately $4.2 \times 10^{7} \mathrm{~A} / \mathrm{s}$ for every resistivity value considered. This finding is consistent with the analysis presented by authors in [9].

\section{B. Rate of quench, $k_{\text {quench }}$}

Fig 6 shows the impact of varying $k_{\text {quench }}$ on the fault current profile, for values of $k_{\text {quench }}$ in the range of $1-100 \mathrm{k} \Omega / \mathrm{s}$.

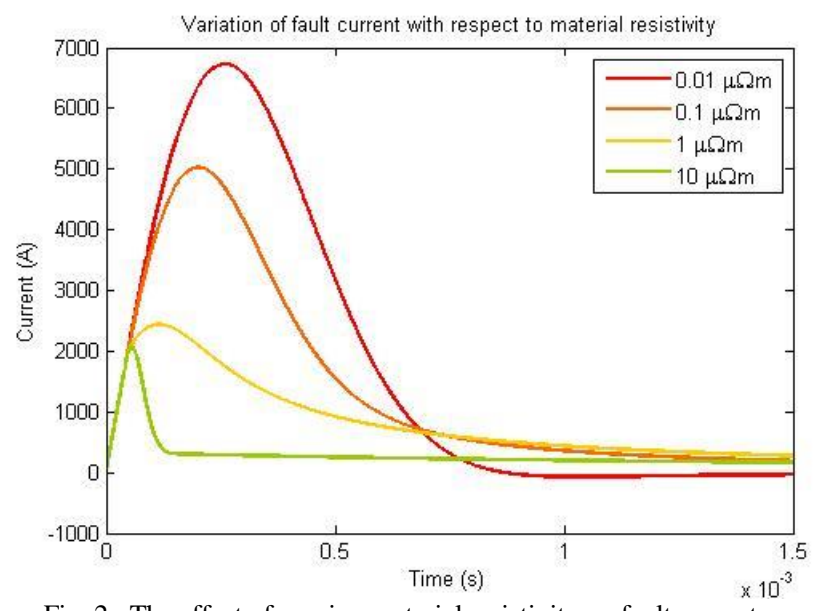

Fig. 2. The effect of varying material resistivity on fault current.

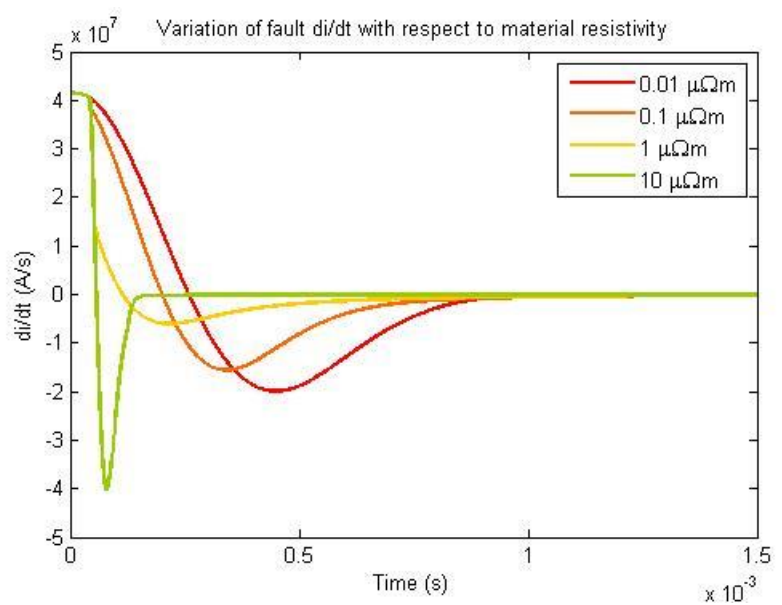

Fig. 3. The effect of varying material resistivity on $d i / d t$ profile.
As $k_{\text {quench }}$ increases and resistance is introduced to the network at a faster rate, the level of damping increases and the fault current is reduced. For example it can be seen that a superconducting material with a $k_{\text {quench }}$ rate of $1 \mathrm{k} \Omega / \mathrm{s}$ will produce a peak fault current of approximately $3.3 \mathrm{kA}$, however this is reduced to around $2.7 \mathrm{kA}$ in a network with a $k_{\text {quench }}$ rate of $100 \mathrm{k} \Omega / \mathrm{s}$.

Moreover as $k_{\text {quench }}$ increases, the time taken for the fault current to reach its peak reduces. Fig. 7, shows that the variation of $k_{\text {quench }}$ has no effect on the initial $d i / d t$ value as it is again approximately $4.2 \times 10^{7} \mathrm{~A} / \mathrm{s}$ for every $k_{\text {quench }}$ value considered.

\section{Rate of creep, $k_{\text {creep }}$}

Under fault conditions the rate at which the temperature of the cable increases will determine the rate at which the cable's resistance continues to creep upwards as its resistivity increases. However as the constraints of the model employed only allows this rate to be approximated, a further sensitivity study was conducted to determine the impact of $k_{\text {creep }}$ on the fault behaviour of the network.

Fig. 8 shows the effect on the fault current through the cable when $k_{\text {creep }}$ is varied. Once again as the rate of $k_{\text {creep }}$ is

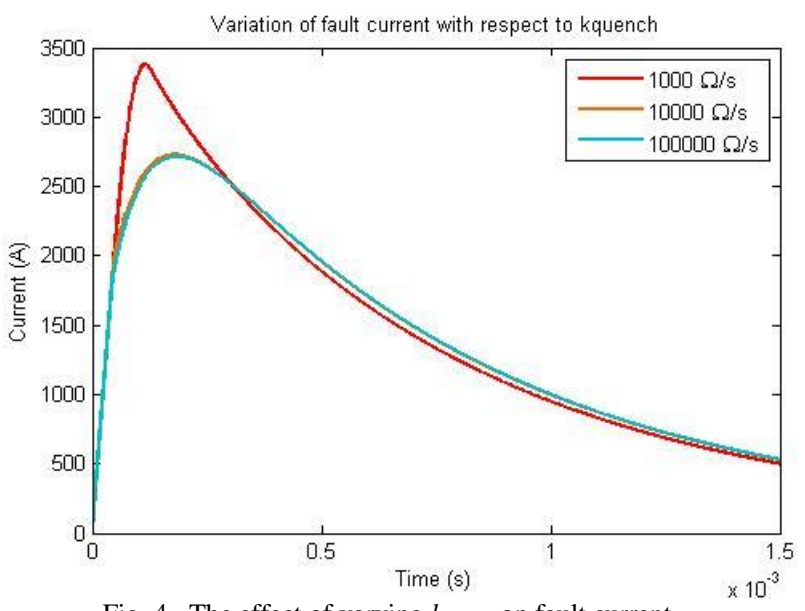

Fig. 4. The effect of varying $k_{\text {quench }}$ on fault current.

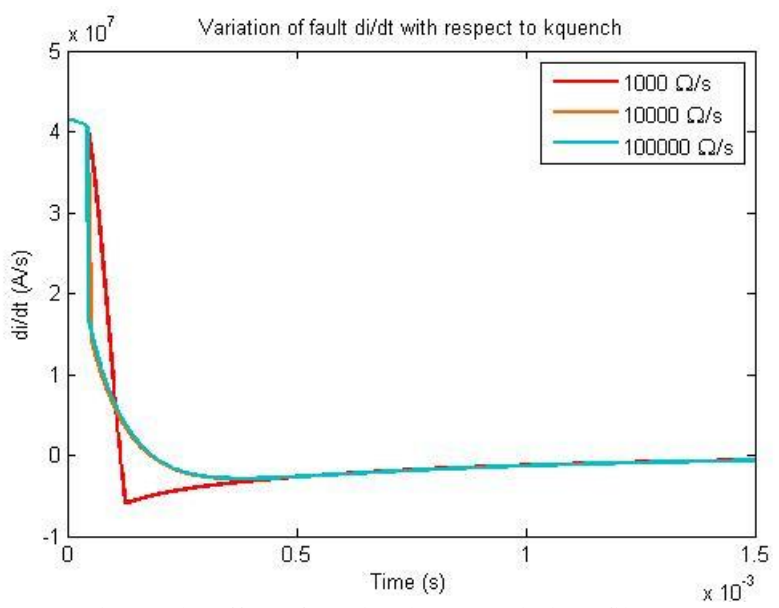

Fig. 5. The effect of varying $k_{\text {quench }}$ on $d i / d t$ profile. 


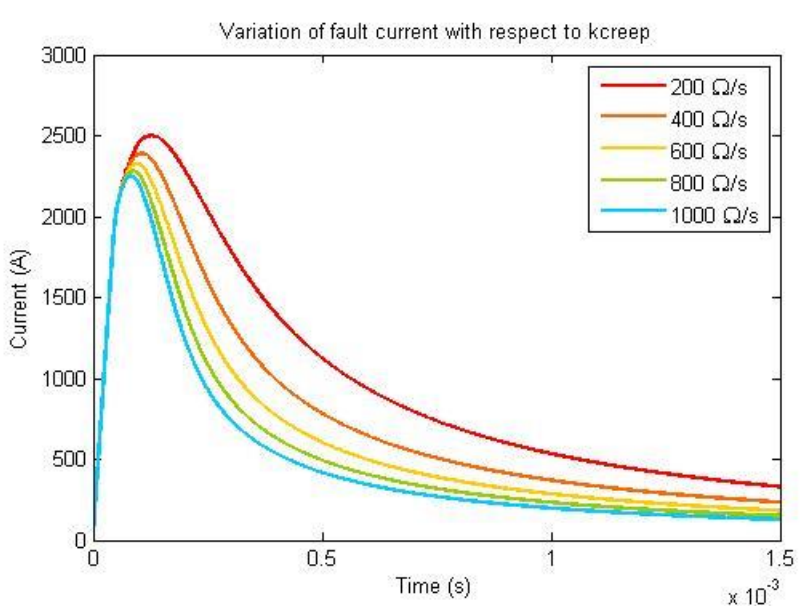

Fig. 8. The effect of varying $k_{\text {creep }}$ on fault current.

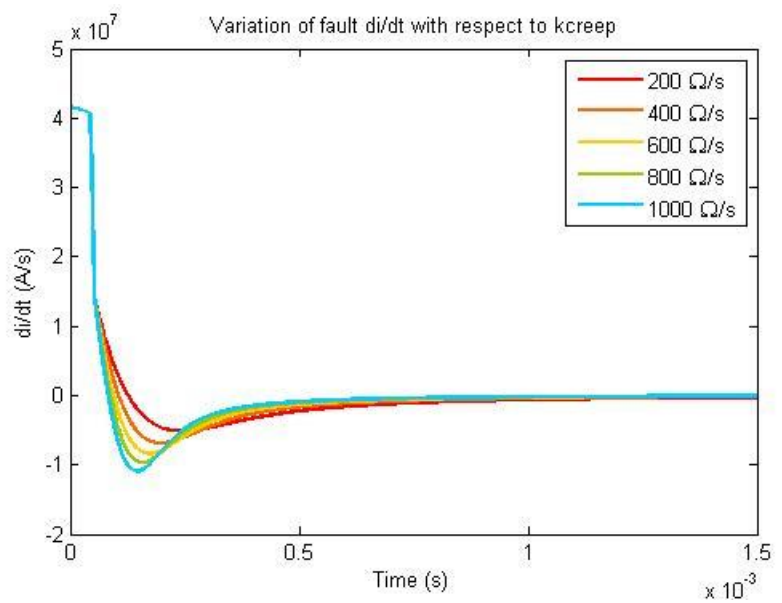

Fig. 9. The effect of varying $k_{\text {creep }}$ on $d i / d t$ profile.

increased the peak fault current magnitude decreases as more resistance is introduced to the network. Fig. 9 shows the $d i / d t$ profile of the faulted network when $k_{\text {creep }}$ is varied. Again there is no significant change to the initial value of $d i / d t$ as it is approximately $4.2 \times 10^{7} \mathrm{~A} / \mathrm{s}$ for the range evaluated in this study.

\section{Network voltage, $V_{C F}$}

In order to establish the extent to which pre-fault network voltage affects the fault current profile, simulations were run varying the pre-fault voltage across the filter capacitor. Fig. 10 shows the fault current profile for network voltages of 270 to $10 \mathrm{kV}$. It can be seen that as the pre-fault network voltage increases from $270 \mathrm{~V}$ to $10 \mathrm{kV}$, the magnitude of the fault current also increases linearly from $2.8 \mathrm{kA}$ to $99 \mathrm{kA}$. Fig. 11 presents the $d i / d t$ profile for network voltages over the same range, showing that as network voltage increases over the same range the rate of change of fault current magnitude also increases from $4 \times 10^{7} \mathrm{~A} / \mathrm{s}$ to $154 \times 10^{7} \mathrm{~A} / \mathrm{s}$.

\section{E. Cable length, $l_{\text {cable }}$}

Figs. 12 and 13 show the how fault response is shaped by the length of the cable where the fault occurs, over a range of

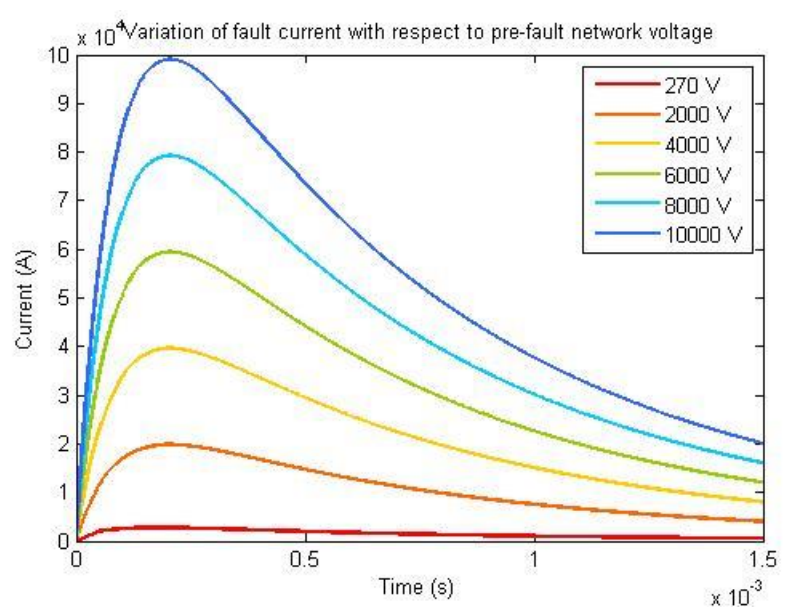

Fig. 10. The effect of varying pre-fault network voltage on fault current.

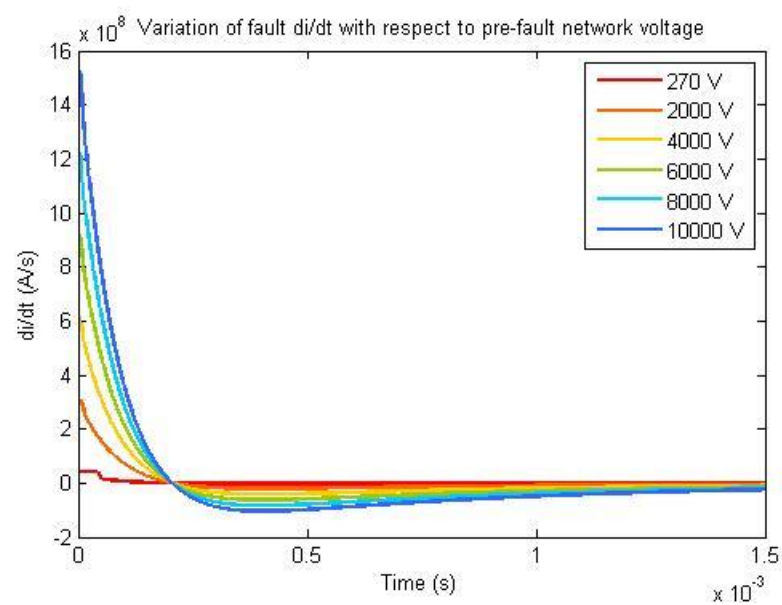

Fig. 11. The effect of varying pre-fault network voltage on $d i / d t$ profile.

$1 \mathrm{~m}$ to $50 \mathrm{~m}$. It can be seen that short cables produce a much higher fault current magnitude than longer cables; however there is little difference in the peak current magnitude when the cable length is between $20 \mathrm{~m}$ and $50 \mathrm{~m}$ in this particular case. The initial $d i / d t$ also increases as the cable length decreases.

\section{F. Cable diameter, $d_{\text {cable }}$}

In order to determine how the choice of cable diameter affects the fault response of the network a sensitivity study was run whilst varying the diameter of the cable through a range of $10 \mathrm{~mm}$ to $30 \mathrm{~mm}$.

As can be seen in Fig. 14 the peak fault current magnitude increases from $1.9 \mathrm{kA}$ to $10.3 \mathrm{kA}$ as the cable diameter increases from $10 \mathrm{~mm}$ to $30 \mathrm{~mm}$ due to the lower levels of resistance achieved during the quench process. The critical current of the superconducting material is also determined by the cross sectional area of the cable, hence as the diameter increases the critical current also increases. In the case of a cable with a diameter of $30 \mathrm{~mm}$, under these specific network parameters, the fault current does not reach the critical current of the material and so does not quench. 


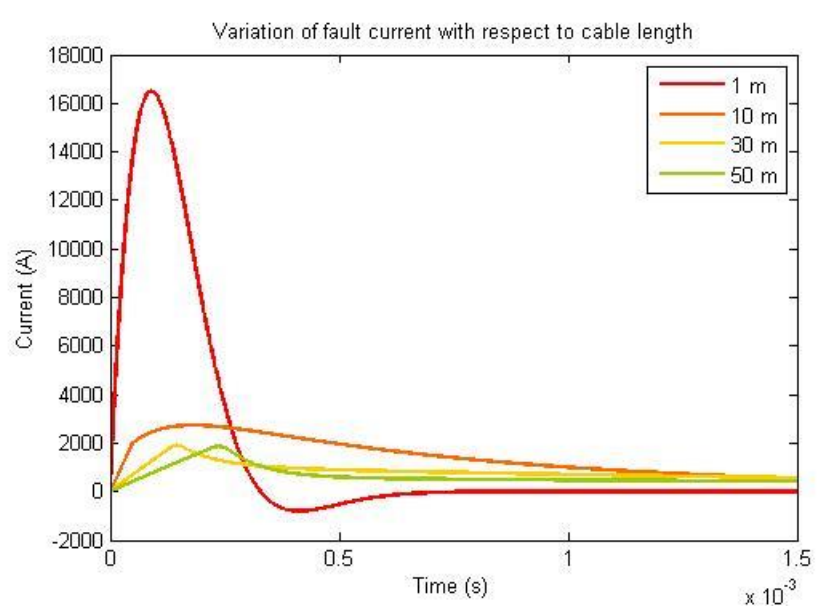

Fig. 12. The effect of varying cable length on fault current.

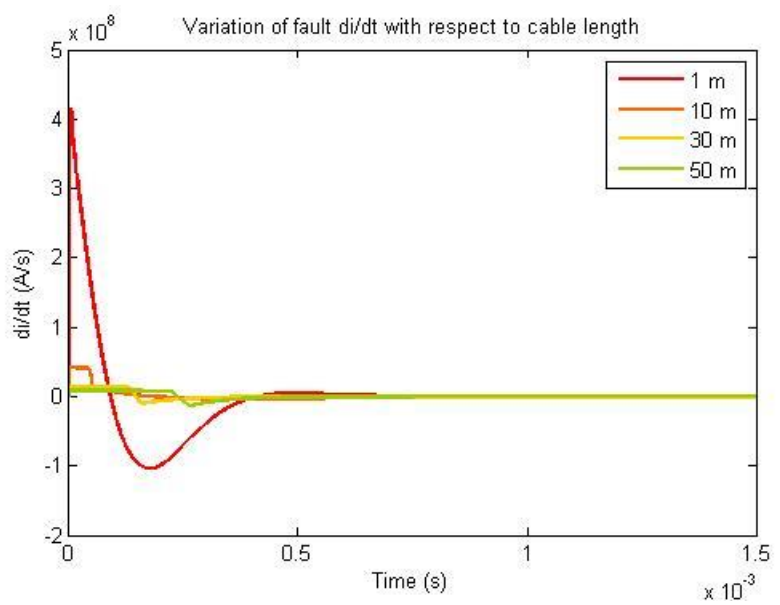

Fig. 13. The effect of varying cable length on $d i / d t$ profile.

\section{DISCUSSION}

In order to determine which parameter(s) the network's fault response is most sensitive to, the peak fault current and initial $d i / d t$ value for each sensitivity study is plotted against a normalised value of the corresponding parameter. Each parameter is normalised to its base case value and shown in Table 1. Figs. 16 and 17 show the sensitivity of the peak fault current and initial $d i / d t$ value respectively, with respect to each of the network parameters studied in the previous section. The sensitivity of each parameter is indicated by the gradient of its corresponding line i.e. a higher sensitivity is indicated by a steeper gradient.

For example it can be seen from Fig 16 that the peak fault current is less sensitive to the quench parameters $\left(k_{\text {quench }}\right.$ and $k_{\text {creep }}$ ) than it is to the pre-fault network voltage or cable diameter. It is also more sensitive to the resistivity of the superconducting material for configurations where this is less than the base case value (i.e. $10 \mu \Omega \mathrm{m}$ ) than for configurations where it is greater than the base case value. As a result the protection strategy or technologies employed may differ depending on the superconducting material chosen. Similarly

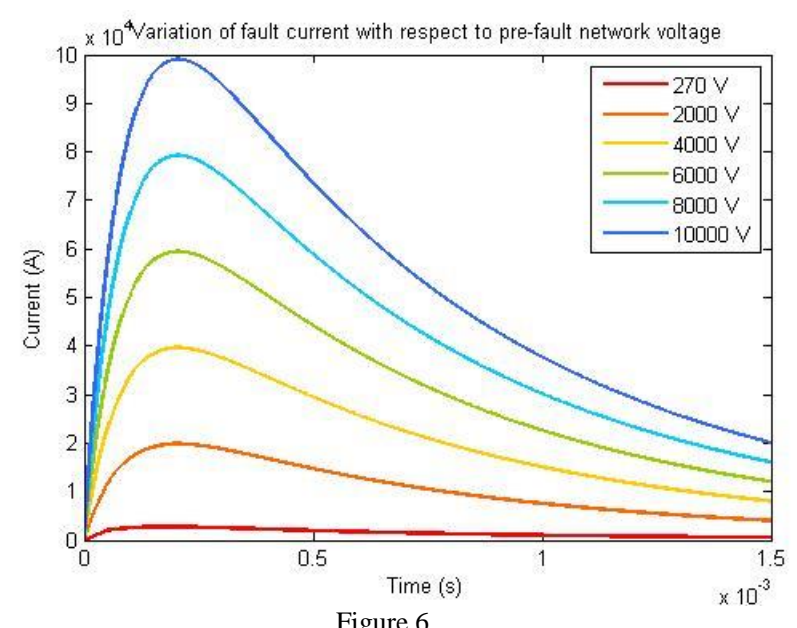

Figure 6

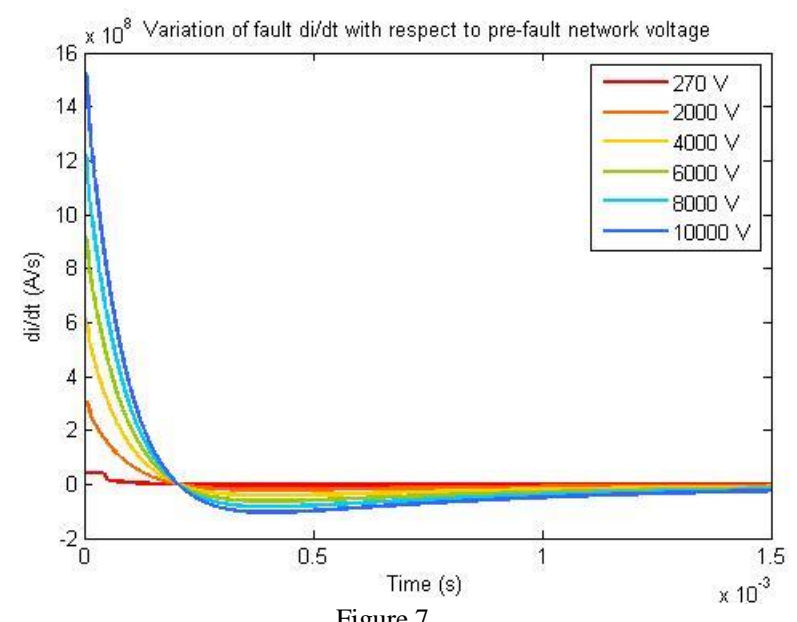

Figure 7

the peak fault current is more sensitive to the length of the cable for configurations where the length is less than the base case value (i.e. $10 \mathrm{~m}$ ) than for configurations where it is greater than the base case value. This may have a significant impact on the protection strategy if shorter cables are used on the network.

Fig. 17 shows that the initial $d i / d t$ value is not sensitive to the resistivity of the superconducting material, quench parameters $\left(k_{\text {quench }}\right.$ and $k_{\text {creep }}$ ) or cable diameter whereas it is highly sensitive to pre-fault network voltage. Additionally it is more sensitive to the length of the cable for configurations where this is less than the base case value (i.e. $10 \mathrm{~m}$ ) than for configurations where it is greater than the base case value. This will once again impact the protection scheme if shorter cables are to be used on the network.

\section{CONCLUSIONS}

This paper has presented an extensive study of the network level fault behaviour of a superconducting DC network. It is expected that the outcomes of these sensitivity studies can be used to inform certain network design choices and protection schemes. 
The architecture of the network may influence its fault behaviour and protection requirements and conversely the protection scheme may shape the network design, however the extent to which they are linked is yet to be determined. One example of the relationship between these themes can be seen with the design of the cable dimensions. Both the length and diameter of the cable have been shown to influence the fault behaviour of the network, and more specifically whether or not the cable will quench. This may be the greatest factor

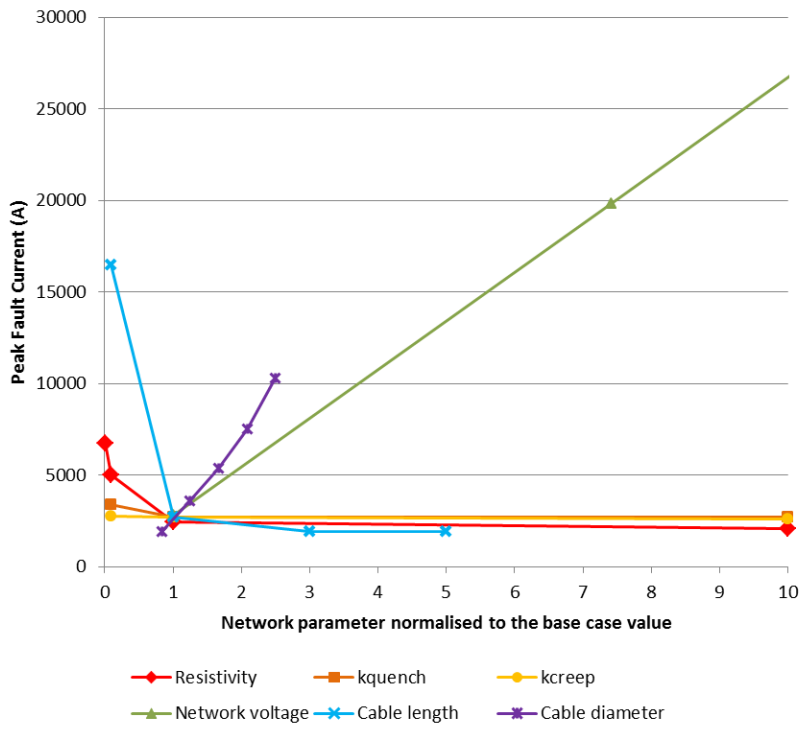

Fig. 16. Sensitivity of peak fault current with respect to normalized network parameters.

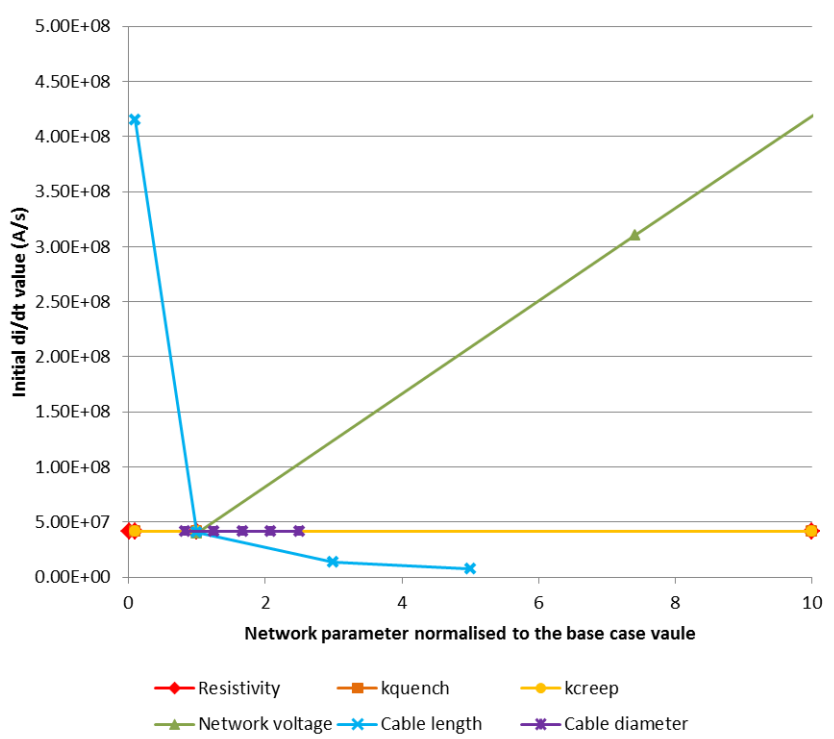

Fig. 17. Sensitivity of initial $d i / d t$ value with respect to normalized network parameters.

which shapes the protection of the network as different strategies may be required for each scenario. For example, if the cables are designed such that they do not quench under fault conditions protection devices such as circuit breakers $(\mathrm{CBs})$ or superconducting fault current limiters (SFCLs) will

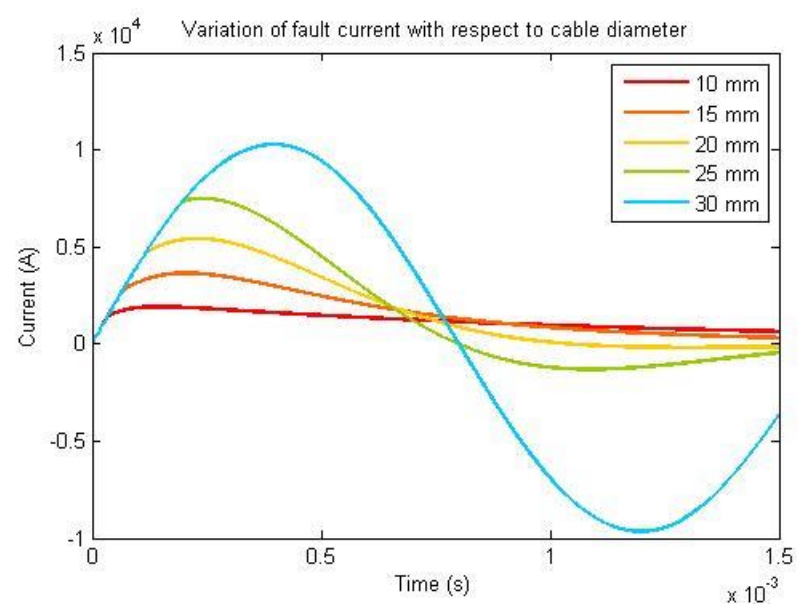

Fig. 14. The effect of varying cable diameter on fault current.

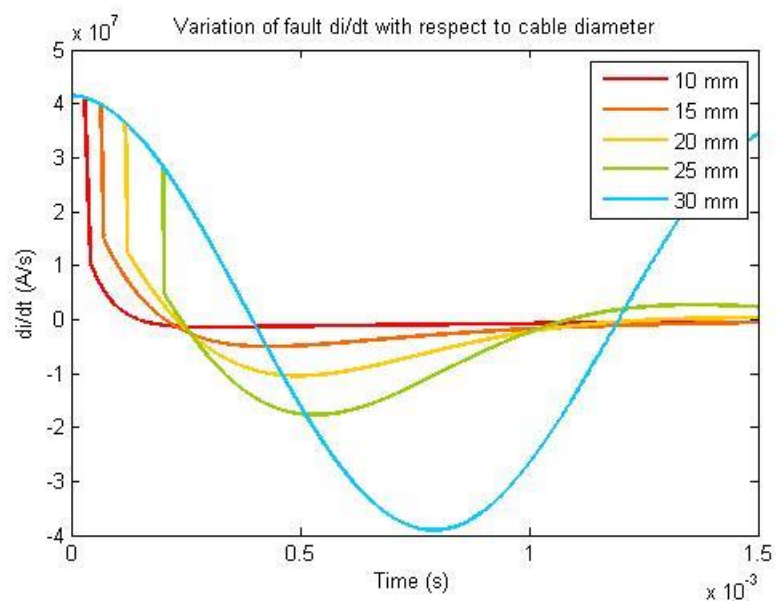

Fig. 15. The effect of varying cable diameter on $d i / d t$ profile.

be required to combat the high prospective fault current. However, if they are designed to quench, the transient resistance will naturally limit the fault current, leading to a less extensive need for high power-rated CBs or SFCLs.

The relationships explored in this paper will be used to inform both network architecture and protection scheme design for proposed TeDP aircraft in future studies.

\section{Acknowledgment}

This work has been carried out as part of the Rolls-Royce UTC programme and with support of the EPSRC.

\section{References}

[1] H. D. Kim, G. V. Brown, and J. L. Felder, "Distributed Turboelectric Propulsion for Hybrid Wing Body," presented at the International Powered Lift Conference, 2008.

[2] C. Ross, M. Armstrong, M. Blackwelder, C. Jones, P. Norman, and S. Fletcher, "Turboelectric Distributed Propulsion Protection System Design Trades," 2014.

[3] C. A. Luongo, P. J. Masson, T. Nam, D. Mavris, H. D. Kim, G. V. Brown, M. Waters, and D. Hall, "Next Generation MoreElectric Aircraft: A Potential Application for HTS 
Superconductors," IEEE Trans. Appl. Supercond., vol. 19, no. 3, pp. $1055-1068$, Jun. 2009.

[4] B. K. Johnson, R. H. Lasseter, F. L. Alvarado, D. M. Divan, H. Singh, M. C. Chandorkar, and R. Adapa, "High-temperature superconducting DC networks," IEEE Trans. Appl. Supercond. vol. 4, no. 3, pp. 115-120, 1994.

[5] K. M. Davies, P. J. Norman, C. E. Jones, S. J. Galloway, and M. Husband, "Examining the Fault Behaviour of a Superconducting Network," presented at the Developments in Power System Protection, 2014.

[6] S. D. A. Fletcher, P. J. Norman, S. J. Galloway, and G. M. Burt, "Determination of protection system requirements for dc unmanned aerial vehicle electrical power networks for enhanced capability and survivability," IET Electr. Syst. Transp., vol. 1, no. 4, pp. 137-147, 2011.

[7] "Electrical Power Systems Simulation - SimPowerSystems Simulink - MathWorks United Kingdom." [Online]. Available: http://www.mathworks.co.uk/products/simpower/. [Accessed: 13-Oct-2014].

[8] J. M. Rowell, "The widely variable resistivity of MgB2 samples," Supercond. Sci. Technol., vol. 16, no. 6, p. R17, Jun. 2003.

[9] S. D. A. Fletcher, P. J. Norman, S. J. Galloway, P. Crolla, and G. M. Burt, "Optimizing the Roles of Unit and Non-unit Protection Methods Within DC Microgrids," IEEE Trans. Smart Grid, vol. 3, no. 4, pp. 2079-2087, Dec. 2012. 